\title{
Prolonged venoarterial extracorporeal membrane oxygenation after transplantation restores functional integrity of severely injured lung allografts and prevents the development of pulmonary graft failure in a pig model
}

György Lang, MD, ${ }^{\mathrm{a}}$ Clemens Aigner, MD, ${ }^{\mathrm{a}}$ Günther Winkler, MD, ${ }^{\mathrm{a}}$ Keso Shkirdladze, MD, ${ }^{\mathrm{b}}$ Wilfried Wisser, MD,
Gerhard Dekan, MD, ${ }^{\mathrm{c}}$ Masaya Tamura, MD, ${ }^{\mathrm{a}}$ Georg Heinze, $\mathrm{PhD},{ }^{\mathrm{d}}$ Dirk Van Raemdonck, MD, ${ }^{\mathrm{a}}$ and Walter Klepetko, $\mathrm{MD}^{\mathrm{a}}$

Objective: Prolonged venoarterial extracorporeal membrane oxygenation support during transplantation provides reduction of pulmonary artery flow and allows for protective ventilation. This approach might have the potential to restore function of lungs that would be unsuitable for transplantation.

\begin{abstract}
Methods: Left lung transplantation was performed on 16 pigs. Lungs from brain-dead animals were stored for 22 hours at $4^{\circ} \mathrm{C}$. Recipients in group $\mathrm{A}(\mathrm{n}=8)$ underwent transplantation without cardiopulmonary support followed by ventilation with $10 \mathrm{~mL} / \mathrm{kg}$ body weight tidal volume. Animals in group $\mathrm{B}(\mathrm{n}=8)$ underwent transplantation during venoarterial extracorporeal membrane oxygenation, which was continued for 22 hours, and received lowtidal-volume $(5 \mathrm{~mL} / \mathrm{kg}$ body weight) ventilation. One hour after transplantation, the right lung was excluded. Graft function was compared immediately after exclusion of the contralateral lung (time point 1 ), 1 hour later (time point 2), and 1 hour after discontinuation of extracorporeal membrane oxygenation (time point 3 ).
\end{abstract}

Results: Four animals in group A did not reach time point 2; all died of pulmonary edema. All animals in group B survived, and at time point 3, the mean $\mathrm{PaO}_{2}$ value was $323 \pm 129 \mathrm{~mm} \mathrm{Hg}$. At time point 2, oxygenation and lung compliance were higher in group B than in group A, whereas pulmonary artery pressure was lower. The same was true when comparing results of group B at time point 3 with results of group A at time point 2.

Conclusions: Transplantation during extracorporeal membrane oxygenation with continued use for 24 hours restores function of damaged donor lungs. This could expand the donor pool through wider use of marginal donors.

According to the report of the International Society for Heart and Lung Transplantation, primary pulmonary graft failure (PGF) accounts for almost one third of early deaths. ${ }^{1}$ PGF is a result of repetitive traumatic episodes involving the allograft. Main contributors are brain death, preservation and storage conditions, and the effects of reperfusion. ${ }^{2}$

PGF usually presents with the clinical picture of severe reperfusion edema. Once edema is established, the standard course of treatment is aggressive ventilation with high pressure patterns together with intravenous inotropic support. However, this course of treatment itself causes further damage to the lung because of overinflation and a further increase in pulmonary artery pressure (PAP).

\footnotetext{
From the Departments of Cardiothoracic Surgery, ${ }^{\mathrm{a}}$ Anaesthesiology, ${ }^{\mathrm{b}}$ and Patho$\operatorname{logy},{ }^{\mathrm{c}}$ and the Core Unit for Medical Statistics and Informatics, ${ }^{\mathrm{d}}$ Medical University of Vienna, Vienna, Austria; and the Department of Thoracic Surgery, Catholic University Leuven, Leuven, Belgium.

Supported by an educational grant from Medtronic.

Received for publication Aug 27, 2008; revisions received Oct 22, 2008; accepted for publication Nov 15, 2008.

Address for reprints: Walter Klepetko, MD, Department of Thoracic Surgery, Medical University of Vienna, Allgemeines Krankenhaus, Währinger Gürtel 18-20, A-1090

Vienna, Austria (E-mail: walter.klepetko@meduniwien.ac.at).

J Thorac Cardiovasc Surg 2009;137:1493-8

$0022-5223 / \$ 36.00$

Copyright (c) 2009 by The American Association for Thoracic Surgery

doi:10.1016/j.jtcvs.2008.11.064
}

The importance of controlled low-pressure perfusion, as well as protective low-tidal-volume ventilation, for recovery of injured lungs has been demonstrated in several clinical and experimental reports. ${ }^{3-7}$ In lung transplantation both controlled low-pressure perfusion and low-tidal-volume ventilation can be provided by venoarterial extracorporeal membrane oxygenation (ECMO). Usually, ECMO is applied for the treatment of already established graft failure. ${ }^{8,9}$ However, it can also be used intraoperatively as an alternative to cardiopulmonary bypass (CPB) and then be prolonged into the postoperative period to provide optimal reperfusion conditions to the transplanted allograft. ${ }^{10}$ In our clinical experience with this approach, we have seen excellent initial graft function, even with very marginal donor organs.

The aim of the study was to investigate the effect of intraoperative and prolonged postoperative ECMO support on the early allograft function of critically injured donor lungs in a standardized experimental transplantation setting.

\section{MATERIALS AND METHODS}

The study was performed in accordance with the Austrian Animal Research Statute (1988) and was approved by the local ethics committee of the Medical Faculty, University of Vienna, Vienna, Austria. Furthermore, the study was conducted in compliance with the principles of laboratory animal care formulated by the National Society for Medical Research and the "Guide for the care and use of laboratory animals," prepared by the 


$$
\begin{aligned}
& \text { Abbreviations and Acronyms } \\
& \text { ARDS }=\text { acute respiratory distress syndrome } \\
& \mathrm{BW} \text { = body weight } \\
& \mathrm{CO}=\text { cardiac output } \\
& \mathrm{CPB}=\text { cardiopulmonary bypass } \\
& \mathrm{ECMO}=\text { extracorporeal membrane oxygenation } \\
& \mathrm{FIO}_{2}=\text { fraction of inspired oxygen } \\
& \text { PAP = pulmonary artery pressure } \\
& \text { PGF = pulmonary graft failure }
\end{aligned}
$$

National Institutes of Health (National Institutes of Health publication no. 96-03, revised 1996).

\section{Experimental Groups}

Thirty-two healthy pigs (German large white pigs) were used. Sixteen served as brain-dead donors, and 16 served as recipients. Four hours after induction of brain death, the donor lungs were harvested and stored for a cold ischemic period of 22 hours. The transplantation procedure was a left single lung transplantation followed by crossclamping of the right lung 1 hour after reperfusion.

The 16 recipient pigs were divided into 2 groups. Group A consisted of 8 pigs undergoing transplantation without ECMO support with standard postoperative ventilation at $10 \mathrm{~mL} / \mathrm{kg}$ body weight (BW). Group B consisted of 8 pigs undergoing transplantation with intraoperative and postoperative (22 hours) ECMO support receiving protective low-tidal-volume postoperative ventilation at $5 \mathrm{~mL} / \mathrm{kg} \mathrm{BW}$.

Functional assessment was performed 10 minutes after exclusion of the contralateral right lung (time point 1), 1 hour later (time point 2), and 22 hours later in group B (ie, 1 hour after weaning from ECMO; time point 3). Graft function was compared between the groups by measuring oxygenation, PAP, dynamic lung compliance, and extravascular lung water content (wet/dry weight ratio).

\section{Donor Procedure}

Anesthesia. An arterial line for invasive pressure monitoring (Smiths Medical, Kirchseeon, Germany) was placed in the right internal carotid artery. A venous line for drugs and fluid replacement was placed in the internal jugular vein. For introduction of a Swan-Ganz catheter (size 7.5F, Vigilance; Edward Lifesciences, Irvine, Calif), the external jugular vein was used. Urine output was monitored through a balloon catheter introduced through a suprasymphyseal lower median laparotomy. Premedication consisted of $20 \mathrm{mg} / \mathrm{kg}$ ketamine (Ketavet; Pharmacia-Upjohn, Uppsala, Sweden) plus $1.76 \mathrm{mg} / \mathrm{kg}$ acepromazine (Vanastress; Vana, Vienna, Austria) administered intramuscularly. Anesthesia was introduced with 15 $\mathrm{mg} / \mathrm{kg}$ thiopental, $15 \mathrm{mg}$ of piritramid (Dipidolor; Janssen-Cilag Pharma, Wien, Austria), and $20 \mathrm{mg}$ of rocuronium bromide (Esmeron; Organon, Oss, The Netherlands) administered intravenously and maintained with $0.1 \mathrm{mg} \cdot \mathrm{kg}^{-1} \cdot \mathrm{h}^{-1}$ piritramid, $10 \mathrm{mg} \cdot \mathrm{kg}^{-1} \cdot \mathrm{h}^{-1}$ propofol (Propofol Fresenius $2 \%$; Fresenius Kabi, Linz, Austria), and $0.1 \mathrm{mg} \cdot \mathrm{kg}^{-1} \cdot \mathrm{h}^{-1}$ rocuronium bromide administered intravenously for muscle relaxation. All animals were fully heparinized with $300 \mathrm{IU} / \mathrm{kg}$ BW Na-Heparin (Heparin Immuno; EBEWE Pharma, Unterach Austria) administered intravenously before cross clamping of the aorta. Animals were intubated with endotracheal tube $\mathrm{Ch} 8$ (Rüsch, Kernen, Germany) and a ventilator (Dräger Primus; Dräger, Luebeck, Germany), and settings were as follows: tidal volume, 10 $\mathrm{mL} / \mathrm{kg} \mathrm{BW}$; frequency, 20/min; fraction of inspired oxygen $\left(\mathrm{FIO}_{2}\right), 0.5$ to 1.0; inspiratory/expiratory time ratio, 1:2; positive end-expiratory pressure, $5 \mathrm{~cm} \mathrm{H}_{2} \mathrm{O}$; and end-tidal $\mathrm{CO}_{2}$ target value, $40 \mathrm{~mm} \mathrm{Hg}$.
Brain death procedure. After induction and maintenance of anesthesia, animals were placed in a ventral decubitus position. A balloon catheter was placed over the dura mater and pushed into the extradural space. Gradual balloon inflation with $25 \mathrm{~mL}$ of fluid $(10+5+5 \mathrm{~mL} / 10 \mathrm{~min}-$ utes and $5 \mathrm{~mL}$ after a further 30 minutes) caused brain death. Lungs were harvested 4 hours later.

Lung harvesting. In contrast to the clinical routine, donor animals did not receive steroid medication to avoid any possible effect on pathways of the brain death-induced lung injury. The brain-dead pig was placed in the dorsal position, and a longitudinal sternotomy was performed. An inflow catheter was placed in the pulmonary artery through a purse-string suture on the right ventricular outflow tract. Both caval veins, together with the ascending aorta, were crossclamped, and the left auricular appendix was incised to provide drainage. The lungs were then perfused with an antegrade flush of $50 \mathrm{~mL} / \mathrm{kg}$ cold low potassium dextran solution (Perfadex; Vitrolife, Gothenburg, Sweden) supplemented with $0.3 \mathrm{~mL} / \mathrm{L}$ Tris buffer. Then an ice slush was placed in both pleural cavities and the mediastinum. During this period, the lungs were ventilated with $50 \%$ oxygen. En bloc harvesting of the heart and lungs together with the esophagus was performed, and before closure of the trachea with a stapler, the donor lungs were moderately inflated. Organs were then wrapped in gauze, placed in an insulated ice bag filled with low potassium dextran solution, and stored at $4^{\circ} \mathrm{C}$ for 22 hours.

\section{Recipient Procedure}

Anesthesia. Anesthesia for the recipient animals was identical as for the donor pigs. One single dose of $5000 \mathrm{IU}$ Na-Heparin and $500 \mathrm{mg}$ of imipenem (Tienam; Merck Sharp \& Dohme, Haarlem, The Netherlands) was administered intravenously. Immunosuppression consisted of a single intravenous dose of $500 \mathrm{mg}$ of methylprednisolone (Solu-Medrol, PharmaciaUpjohn) administered immediately before reperfusion.

Implantation. The donor lung was then reimplanted with 4-0 polydioxanone running sutures for the bronchial anastomosis and 5-0 Prolene sutures for the pulmonary artery and left atrium. The implanted lung underwent retrograde and antegrade deairing and flushing according to standard procedures. Thereafter, the arterial clamp was partially released for 10 minutes to provide controlled reperfusion. One hour later, the bronchus and artery of the contralateral right lung were crossclamped. Ventilation to the transplanted lung was begun during reperfusion by using the standard method in group A and by using low tidal volumes in group B. At the end of the experiments, animals were killed by clamping of the left pulmonary artery.

ECMO management. For the animals in group B, the Medtronic Biomedicus portable bypass system with a hollow-fiber oxygenator (Medtronic CPMPCB Affinity BPX-80; Medtronic, Minneapolis, Minn) and an integrated heat exchanger was used for ECMO support. After thoracotomy, direct central cannulation of the ascending aorta (Medtronic DLP 22F Curved Tip) and the inferior caval vein (Medtronic DLP 32F Single Stage) was performed. Both the cannulae and the circuit were heparin coated (Medtronic Carmeda BioActive Surface). Priming solution was $200 \mathrm{~mL}$ of Ringer's Lactate solution. The flow was set at $50 \%$ of initial cardiac output (CO). This support was maintained throughout the whole transplantation procedure and continued for a further 22 hours. Thereafter, the pig was gradually weaned from ECMO. One hour later, the final functional assessment (time point 3) was performed.

\section{Assessments}

All arterial blood gas samples were taken from the right internal carotid artery after a test ventilation period of at least 10 minutes at an $\mathrm{FIO}_{2}$ of 1.0 (ABL800 Flex Radiometer, Copenhagen, Denmark). Heart rate, arterial blood pressure, oxygen saturation, central venous pressure, and PAP were continuously monitored (PPG Hellige, Freiburg, Germany). Dynamic compliance was measured with a volume-controlled ventilator (Dräger Primus; Drägerwerk, Luebeck, Germany). Lung biopsy samples were taken from the anterior margin of the lower lobe. 
TABLE 1. Baseline variables

\begin{tabular}{|c|c|c|c|}
\hline & Group A & Group B & $\begin{array}{c}P \text { value } \\
(t \text { test })\end{array}$ \\
\hline Recipient weight (kg) & $54 \pm 4$ & $57 \pm 8$ & $>.2$ \\
\hline Donor weight $(\mathrm{kg})$ & $59 \pm 5$ & $60 \pm 9$ & $>.2$ \\
\hline $\mathrm{P} / \mathrm{F}$ ratio before $\mathrm{BD}(\mathrm{mm} \mathrm{Hg})$ & $500 \pm 82$ & $532 \pm 44$ & $>.2$ \\
\hline Compliance before $\mathrm{BD}\left(\mathrm{mL} / \mathrm{cm} \mathrm{H}_{2} \mathrm{O}\right)$ & $31 \pm 5$ & $33 \pm 5$ & $>.2$ \\
\hline Wet/dry ratio $\%$ before BD & $82.1 \pm 2.6$ & $80.7 \pm 2.9$ & $>.2$ \\
\hline Mean PAP before BD (mm Hg) & $19.9 \pm 1.1$ & $20 \pm 1.9$ & $>.2$ \\
\hline Time BD-CC (min) & $268 \pm 37$ & $263 \pm 72$ & $>.2$ \\
\hline $\mathrm{P} / \mathrm{F}$ ratio $4 \mathrm{~h}$ after $\mathrm{BD}(\mathrm{mm} \mathrm{Hg})$ & $501 \pm 48$ & $505 \pm 33$ & $>.2$ \\
\hline Compliance $4 \mathrm{~h}$ after $\mathrm{BD}\left(\mathrm{mL} / \mathrm{cm} \mathrm{H}_{2} \mathrm{O}\right)$ & $32 \pm 8$ & $32 \pm 5$ & $>.2$ \\
\hline Wet/dry ratio $\% 4 \mathrm{~h}$ after $\mathrm{BD}$ & $82.4 \pm 1.3$ & $80.7 \pm 2.9$ & $>.2$ \\
\hline Mean PAP $4 \mathrm{~h}$ after BD (mm Hg) & $18.1 \pm 2.0$ & $18 \pm 2.1$ & $>.2$ \\
\hline CIT (min) & $1281 \pm 76$ & $1312 \pm 80$ & $>.2$ \\
\hline Mean PAP, baseline recipient $(\mathrm{mm} \mathrm{Hg})$ & $20.8 \pm 2.3$ & $20.3 \pm 1.6$ & $>.2$ \\
\hline
\end{tabular}

The biopsy sample was weighed and then dried to a constant weight at $80^{\circ} \mathrm{C}$. Lung water was calculated by using the following formula:

$\%$ Tissue water $=([$ Wet weight - Dry weight $] /$ Wet weight $) \times 100$.

We checked the distributions of all variables for symmetry by comparing means with medians and ranges and found no unusually skewed distributions. Therefore animal characteristics were described as means and standard deviations and compared between groups with independent-samples $t$ tests. Outcome measures were compared between groups by using repeated-measures analysis of variance specifying a first-order autoregressive covariance structure. An interaction of group with time was assessed, and if the interaction was significant, Bonferroni-Holm-corrected $P$ values comparing groups at different time points were computed. Otherwise, the group difference was assumed to be equal across all time points, and a common $P$ value was computed from the repeated-measures analysis of variance model. This analysis was repeated, replacing original values with their ranks, to see whether results depended on the assumption of normal distribution. There was no difference in the pattern of significances between both analyses suggesting robust results. There were also no relevant changes by specifying different types of covariance structures. Survival was compared with the exact log-rank test. ${ }^{11}$ All tests were 2-sided. The SAS System (version 9.2, 2008; SAS Institute, Inc, Cary, NC) was used for statistical computations.

\section{RESULTS}

There was no important difference between the study groups regarding baseline variables (Table 1).

\section{Survival}

Survival was better in group B than in group A (100\% vs $50 \%$ at time point $2, P=.026$ ).

In group A all animals died of lung edema and hypoxia. One pig died 28 minutes after reperfusion and did not reach time point 1 . Three other pigs died before time point 2 . Of the remaining 4 pigs, 2 died immediately after time point 2 , and the others died 3 hours later.

In group B all animals survived and were successfully weaned from ECMO after 22 hours except 1. This animal showed critical hemodynamic instability after 3 weaning

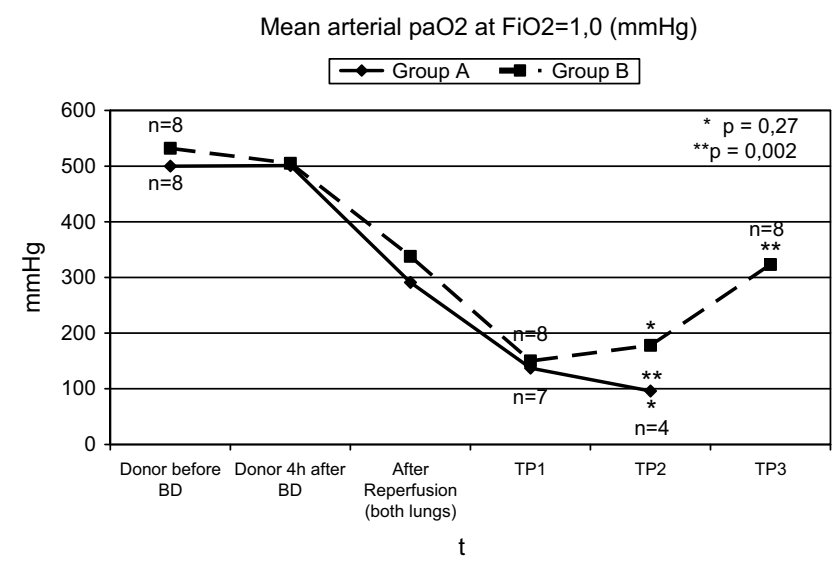

FIGURE 1. Mean arterial $\mathrm{PaO}_{2}$ at a fraction of inspired oxygen $\left(\mathrm{FIO}_{2}\right)$ of 1.0 in function of time. Values are shown as mean levels. $B D$, Brain death; $T P 1$, time point 1 (immediately after exclusion of the right lung); TP2, time point 2 (1 hour after exclusion of the right lung); TP3, time point 3 (1 hour after discontinuation of extracorporeal membrane oxygenation).

attempts but without signs of lung edema. The other 7 pigs remained in stable condition after time point 3 , and no trend toward deterioration was observed over the following 3 hours. Thereafter, the experiments were terminated.

\section{Functional Performance}

Oxygenation. There was no difference between group A and group $\mathrm{B}$ regarding $\mathrm{PaO}_{2} / \mathrm{FIO}_{2}$ ratio either after reperfusion $(291 \pm 88$ vs $338 \pm 73 \mathrm{~mm} \mathrm{Hg}$, respectively; $P>.2)$ or 10 minutes after becoming dependent from the allograft (time point $1 ; 137 \pm 148$ vs $150 \pm 87 \mathrm{~mm} \mathrm{Hg}$, respectively; $P>.2$ ). At time point 2 , the mean $\mathrm{PaO}_{2} / \mathrm{FIO}_{2}$ ratio of the surviving 4 animals in group A was worse than that in group B $(96 \pm 41$ vs $178 \pm 114 \mathrm{~mm} \mathrm{Hg}, P>.2)$. One hour after weaning from ECMO (time point 3 ), pigs in group B showed excellent allograft function $(323 \pm 129 \mathrm{~mm} \mathrm{Hg})$. When the corresponding values for 1-hour dependency from the new lung in the 2 groups (group A, time point 2; group B, time point 3) were compared, better results were seen in group $\mathrm{B}(96 \pm 41$ vs $323 \pm 129 \mathrm{~mm} \mathrm{Hg}, P=.002$; Figure 1$)$.

Pulmonary artery pressure. Mean PAP was higher in group A than in group B both after pneumonectomy and immediately after reperfusion $(28.5 \pm 4.5$ vs $18.6 \pm 3.9$ $\mathrm{mm} \mathrm{Hg}, P=.002$, and $28.9 \pm 7.2$ vs $18.8 \pm 2.1 \mathrm{~mm} \mathrm{Hg}$, $P=.002$, respectively). At time point 1 , there was also some difference in mean PAP values between group A and group B (38.4 \pm 7.7 vs $32.9 \pm 7.1 \mathrm{~mm} \mathrm{Hg}$, respectively; $P=.048)$. At time point 2 , the mean PAP of the surviving 4 animals in group A was higher than that in group B (45.3 $\pm 4.1 \mathrm{vs} 33.6 \pm 4 \mathrm{~mm} \mathrm{Hg}, P=.006$ ). One hour after weaning from ECMO (time point 3), pigs in group B showed almost normal mean PAPs $(24.1 \pm 5.4 \mathrm{~mm} \mathrm{Hg})$. Again, when comparing this value with the mean PAP at time point 2 in group A $(45.3 \pm 4.1 \mathrm{~mm} \mathrm{Hg})$, the difference is highly in favor of group B $(P<.001)$. 
Lung compliance. At time point 1 , compliance was $16 \pm 8$ $\mathrm{mL} / \mathrm{cm} \mathrm{H}_{2} \mathrm{O}$ in group A versus $13 \pm 3 \mathrm{~mL} / \mathrm{cm} \mathrm{H}_{2} \mathrm{O}$ in group $\mathrm{B}(P>.2)$, and at time point 2 , it was $11 \pm 1 \mathrm{~mL} / \mathrm{cm} \mathrm{H}_{2} \mathrm{O}$ vs $14 \pm 3 \mathrm{~mL} / \mathrm{cm} \mathrm{H}_{2} \mathrm{O}$, respectively $(P>.2)$. Again, comparing compliance of group A at time point 2 with compliance of group $\mathrm{B}$ at time point 3 , the allografts in the ECMO group performed better $\left(11 \pm 1\right.$ vs $\left.16 \pm 5 \mathrm{~cm} \mathrm{H}_{2} \mathrm{O}, P>.2\right)$.

Wet/dry ratio. Differences between study groups regarding lung water content could be due to chance. The wet/ dry ratio was $82.7 \% \pm 4.2 \%$ in group A versus $76.0 \%$ $\pm 7.4 \%$ in group B at time point $1(P>.2), 78.5 \% \pm$ $3.5 \%$ in group A versus $76.8 \% \pm 5.3 \%$ in group B at time point $2(P>.2)$, and $76.9 \% \pm 9.1 \%$ in group B at time point 3 .

\section{DISCUSSION}

The findings of this study demonstrate that severely injured lung allografts can successfully be transplanted when optimal conditions during the initial reperfusion period are provided. These organs, derived from braindead donors and undergoing a 22-hour cold ischemic storage period, uniformly result in lung edema and PGF when transplanted in a conventional way. The combination of a reduction of the circulatory blood volume passing the pulmonary vascular bed during an extended reperfusion period of 22 hours together with the application of protective low-volume ventilation, however, allows the allograft to recover and prevents the onset of a cascade of events that ultimately would result in development of PGF.

The starting point of lung injury during transplantation begins with the brain death of the donor. ${ }^{12,13}$ The nonphysiologic composition and temperature of the cold preservation fluid represent further stresses to the endothelium. This is followed by formation of reactive oxygen species during cold ischemic storage. Endothelial cells under such conditions become sensitive to mechanical forces and react with electrophysiologic and biochemical consequences. ${ }^{2}$

Given the complexity of lung ischemia-reperfusion injury mechanisms, there are a number of possible approaches to counteract this, such as limiting the deleterious effects of brain death, optimizing perfusion and storage conditions, and, most importantly, interrupting the developing cascade of injury during the reperfusion itself.

The first data on the importance of controlled reperfusion were derived from experimental studies. Okamoto, Allen, and colleagues ${ }^{14,15}$ demonstrated that 20 minutes of controlled reperfusion are superior to 10 minutes only after regional ischemia in hearts. Halldorsson and associates ${ }^{3}$ and Bhabra and coworkers ${ }^{16}$ proved that reduction of PAP during the first 10 minutes of reperfusion of transplanted lungs leads to a clear reduction in the severity of pulmonary reperfusion injury. However, there are no experimental data available on whether a substantial prolongation of such a controlled reperfusion period could be of further benefit.
Additional information about the importance of controlled reperfusion comes from clinical experience with bilateral sequential lung transplantation performed without CPB. During this procedure, the first transplanted lung is subjected to complete $\mathrm{CO}$ during the implantation of the second lung. As a consequence, tissue edema formation and radiographic infiltrates in the first transplanted lung are common and known as the first lung syndrome. For these reasons, some centers prefer to perform bilateral transplantation routinely with $\mathrm{CPB}$, which offers the possibility for improved reperfusion conditions, especially for the first lung. ${ }^{17}$ Similar results derive from the experience with ex vivo lung assessment. Steen and colleagues ${ }^{18}$ investigated lung allografts of non-heart beating donors after preservation with topical cooling. They reported the importance of keeping the PAP at less than $20 \mathrm{~mm} \mathrm{Hg}$ during functional assessment of the grafts by means of ex vivo perfusion. The same principle was applied by Egan and associates ${ }^{19}$ for ex vivo assessment of human lungs. ${ }^{19}$ All these data suggest that the reduction of pulmonary artery flow during early reperfusion is crucial for the prevention of severe reperfusion injury. However, the optimal length of time to provide such reperfusion conditions remains undefined thus far.

Prolongation of controlled reperfusion into the postoperative period is possible with venoarterial ECMO. Ko and coworkers $^{20}$ reported their experience in 5 patients with $\mathrm{PPH}$, in whom they used ECMO during lung transplantation and for several hours thereafter. All patients had an uneventful transplantation and had excellent organ function after the procedure. Our own early experience with lung transplantation during intraoperative and postoperatively prolonged ECMO was gained from patients with severe pulmonary hypertension. Seventeen patients underwent transplantation in this way, and initial organ function was excellent in all of them. ${ }^{10}$ After this experience, we expanded the use of ECMO for lung transplantation in our department until it finally replaced the use of CPB as the standard method completely. ${ }^{9}$ In addition to the resulting reduction in pulmonary flow, it was possible to apply extremely protective ventilation conditions.

The importance of such a low-pressure, low-tidal-volume ventilation for prevention of lung damage, as well as for recovery of already injured lungs, has been demonstrated repeatedly. Traditional approaches to mechanical ventilation use tidal volumes of 10 to $15 \mathrm{~mL} / \mathrm{kg} \mathrm{BW}$. In animal experiments it has been demonstrated that ventilation with such large tidal volumes causes disruption of the pulmonary epithelium and endothelium and subsequently leads to lung inflammation and release of inflammatory mediators. ${ }^{21,22}$ Similar experience comes from a single lung transplantation study in rat lungs. ${ }^{23}$ These experimental findings are in line with clinical observations. In a controlled, multicenter randomized trial of the Acute Respiratory Distress Syndrome (ARDS) network on 861 patients with acute lung injury or 
ARDS, the authors were able to demonstrate that a less aggressive respiratory pattern with lower tidal volumes than traditionally used resulted in improved clinical outcome. ${ }^{5}$ These data support the view that aggressive ventilation patterns, although sometimes necessary to provide adequate oxygenation, contribute to the exacerbation and perpetuation of lung injury itself. This is precisely the situation that is of importance for a lung allograft in the period of reperfusion.

ECMO has been used in a wide spectrum of indications, including clinical lung transplantation and treatment of severe lung injury. Recently, its efficiency for treatment of severe forms of ARDS has been described. ${ }^{24}$ In this situation ECMO maintains gas exchange and provides optimal conditions for lung recovery by allowing the use of nondamaging ventilator settings. A similar approach, based on the concept "to put the lung to rest" to achieve better conditions for recovery, was described by Iglesias and associate. ${ }^{25}$ They used near-static ventilation for patients with severe ARDS while providing gas exchange over a pumpless extracorporeal membrane system (Novalung, Talheim, Germany). Similar experience has been gained with the use of ECMO for the treatment of already established posttransplantation graft failure. $^{26-30}$ From our own early experience, we were impressed by the observation that the transplanted lungs that were in even very severe forms of reperfusion edema were able to recover within a short period of time once venoarterial ECMO was installed. From all these reports, it becomes evident that venoarterial ECMO treatment not only maintains vital functions during periods of severe lung injury but even more directly contributes to improved recovery of the lung by means of 2 factors: reduction of pulmonary artery flow and avoidance of harmful ventilator settings.

However, it is certainly difficult to evaluate this clinical experience on an objective basis given the heterogeneity of clinical situations. For this reason, we decided to test the validity of the hypothesis in a standardized experimental model of severely injured lung allografts. In this model the combined injury caused by brain death with a prolonged ischemic time of 22 hours uniformly resulted in the development of severe PGF in group A, in which lungs were transplanted in a conventional way. The addition of brain death in our donors obviously contributed significantly to the resulting severe organ damage because Steen and colleagues, ${ }^{18}$ in a similar setting but without brain death, reported a far better functional performance of donor lungs. Assessments in this experiment were performed in accordance to the time points of clinical importance, which are 10 minutes after crossclamping of the contralateral lung (time point 1) and 1 hour thereafter (time point 2). Because animals in group B at that time were undergoing partial ECMO support, they were also investigated at time point 3 (1 hour after weaning from ECMO; ie, after complete dependency on the trans- planted lung). Results from time point 3 in group B were also compared with results from time point 2 in group $A$ to compare the situation of 1 hour of complete dependency on the transplanted lung in both groups and because none of the animals of group A survived long enough to reach time point 3 . The results obtained in this setting were striking. All animals of group A had severe reperfusion edema and died before or soon after time point 2 . In contrast, all except 1 of the animals in group B were successfully weaned from ECMO and showed excellent graft function, which was maintained for several hours. The 1 animal that could not be weaned from ECMO was unstable because of hemodynamic problems and not because of PGF. This finding was paralleled by clearly superior functional parameters in group B. The observation that the wet/dry ratio in group $\mathrm{A}$ at time point 2 was not significantly higher than that in group $B$ is controversial and probably due to the fact that 4 animals with signs of lung edema already died thus far, and the results are reflecting the remaining animals who performed better. However, we consider wet/dry ratio as a weak parameter in this context, as far as other investigators also registered a decrease in lung water content after experimental reperfusion conditions. ${ }^{19,31}$

These results provide evidence for several important facts. Lung damage in our model was caused by a long cold ischemic period in lungs that was triggered by brain death. This combination obviously results in such severe damage to the graft that development of severe PFG becomes an inevitable consequence under conventional implantation strategies. Transplantation on venoarterial ECMO and prolongation of this support through a 22-hour period of reperfusion, however, maintains hemodynamic and oxygenatory stability during this critical period of time and protects the transplanted lung from further reperfusion injury. This period of 22 hours is obviously sufficiently long enough that the graft can recover from the injury obtained during brain death and ischemic storage and can provide excellent organ function thereafter. This suggests that the damage that donor organs receive during transplantation occurs in a 2-stage process. In stage 1 endothelial cell injury and increase in capillary permeability occur during the storage and implantation phase. The real injury to the graft, however, derives from the second stage, when the preinjured graft becomes prone to nonoptimal reperfusion conditions. During this period, the injury to the lungs proceeds to severe PGF. One can conclude that the importance of these reperfusion conditions and the length of the critical time period have been underestimated thus far. Venoarterial ECMO, with the previously mentioned features of reduction of $\mathrm{CO}$ and passing the pulmonary vascular bed, in combination with protective ventilation obviously has the potential to prevent further progress of graft damage and to allow for rapid healing of the already existing injuries. However, the exact period of time needed for lungs to recover from the ischemic damage is currently 
unknown. Obviously, it clearly exceeds the always described period of the first 10 to 15 minutes after transplantation. Based on our clinical and experimental experience, this time period should be 8 to 12 hours if dealing with early signs of PGF and using ECMO in a preemptive manner and between 24 and 48 hours if treating manifest PGF. ECMO should be applied early in the course of lung dysfunction after transplantation to avoid further damage from barotrauma and hemodynamic instability from maximal ventilatory support.

These findings might well be of importance for the use of marginal donor lungs and might help to expand the current organ donor pool. This would be a valuable addition to the current efforts of ex vivo reconditioning of donor lungs. ${ }^{18,19,32}$

\section{References}

1. Trulock EP, Christie JD, Edwards LB, Boucek MM, Aurora P, Taylor DO, et al. Registry of the International Society for Heart and Lung Transplantation: twentyfourth official adult lung and heart-lung transplantation report-2007. J Heart Lung Transplant. 2007;26:782-95.

2. de Perrot M, Liu M, Waddell TK, Keshavjee S. Ischemia-reperfusion-induced lung injury. Am J Respir Crit Care Med. 2003;167:490-511.

3. Halldorsson AO, Kronon M, Allen BS, Rahman S, Wang T, Layland M, et al. Controlled Reperfusion after lung ischemia: implications for improved function after lung transplantation. J Thorac Cardiovasc Surg. 1998;115:415-25.

4. Bhabra MS, Hopkinson DN, Shaw TE, Onwu N, Hooper TL. Controlled reperfusion protects lung grafts during a transient early increase in permeability. Ann Thorac Surg. 1998;65:187-92.

5. The Acute Respiratory Distress Syndrome Network. Ventilation with lower tidal volumes as compared with traditional tidal volumes for acute lung injury and the acute respiratory distress syndrome. $N$ Engl J Med. 2000;342:1301-8.

6. Hemmila MR, Rowe SA, Boules TN, Miskulin J, McGillicuddy JW, Schuerer DJ, et al. Extracorporeal life support for severe acute respiratory distress syndrome in adults. Ann Surg. 2004;240:595-607.

7. Iglesias M, Martinez E, Badia JR, Macchiarini P. Extrapulmonary ventilation for unresponsive severe acute respiratory distress syndrome after pulmonary resection. Ann Thorac Surg. 2008;85:237-44.

8. Glassman LR, Keenan RJ, Fabrizio MC, Sonett JR, Bierman MI, Pham SM, et al. Extracorporeal membrane oxygenation as an adjunct treatment for primary graft failure in adult lung transplant recipients. J Thorac Cardiovasc Surg. 1995;110: 723-7.

9. Aigner C, Wisser W, Taghavi S, Lang G, Jaksch P, Czyzewski D, et al. Institutional experience with extracorporeal membrane oxygenation in lung transplantation. Eur J Cardiothorac Surg. 2007;31:468-74.

10. Pereszlenyi A, Lang G, Steltzer H, Hetz H, Kocher A, Neuhauser P, et al. Bilateral lung transplantation with intra- and postoperatively prolonged ECMO support in patients with pulmonary hypertension. Eur J Cardiothorac Surg. 2002;21:858-63.

11. Heinze G, Gnant M, Schemper M. Exact log rank tests for unequal follow-up. Biometrics. 2003;59:1151-7.

12. Avlonitis VS, Fisher AJ, Kirby JA, Dark JH. Pulmonary transplantation: the role of brain death in donor lung injury. Transplantation. 2003;75:1928-33.

13. Bittner HB, Kendall SW, Chen EP, Craig D, Van Trigt P. The effects of brain death on cardiopulmonary hemodynamics and pulmonary blood flow characteristics. Chest. 1995;108:1358-63.
14. Okamoto F, Allen BS, Buckberg GD, Bugyi H, Leaf J. Studies of controlled reperfusion after ischemia. XIV. Reperfusion conditions: importance of ensuring gentle versus sudden reperfusion during relief of coronary occlusion. $J$ Thorac Cardiovasc Surg. 1986;92:613-20.

15. Allen BS, Okamoto F, Buckberg GD, Bugyi H, Leaf J. Studies of controlled reperfusion after ischemia. XV. Immediate functional recovery after 6 hours of regional ischemia by careful control of conditions of reperfusion and composition of the reperfusate. J Thorac Cardiovasc Surg. 1986;92:621-35.

16. Bhabra MS, Hopkinson DN, Shaw TE, Hooper TL. Critical importance of the first 10 minutes of lung graft perfusion after hypothermic storage. Ann Thorac Surg. 1996;61:1631-5.

17. Aeba BP, Griffith BP, Kormos RL, Armitage JM, Gasior TA, Fuhrman CR, et al. Effect of cardiopulmonary bypass on early graft dysfunction in clinical lung transplantation. Ann Thorac Surg. 1994;57:715-22.

18. Steen S, Liao Q, Wierup PN, Bolys R, Pierre L, Sjöberg T. Transplantation of lungs from non-heart-beating donors after functional assessment ex vivo. Ann Thorac Surg. 2003;76:244-52.

19. Egan TM, Haithcock JA, Nicotra WA, Koukoulis G, Inokawa H, Sevala M, et al. Ex vivo evaluation of human lungs for transplant suitability. Ann Thorac Surg. 2006;81:1205-13.

20. Ko WJ, Chen YS, Luh SP, Chu SH. Extracorporeal membrane oxygenation support for single-lung transplantation in patients with primary pulmonary hypertension. Transplant Proc. 1999;31:166-8.

21. Tsuno K, Miura K, Takeya M, Kolobow T, Morioka T. Histopathologic pulmonary changes from mechanical ventilation at high peak airway pressures. Am Rev Respir Dis. 1991;143:1115-20.

22. Tremblay L, Valenza F, Ribeiro SP, Li J, Slutsky AS. Injurious ventilatory strategies increase cytokines and c-fos m-RNA expression in an isolated rat lung model. J Clin Invest. 1997;99:944-52.

23. de Perrot M, Imai Y, Ranieri VM, Waddell TK, Liu M, McRae K, et al. Impact of ventilator induced lung injury on the development of reperfusion injury in a rat lung transplant model. J Thorac Cardiovasc Surg. 2002;124:1137-44.

24. Hemmila MR, Rowe SA, Boules TN, Miskulin J, McGillicuddy JW, Schuerer DJ, et al. Extracorporeal life support for severe acute respiratory distress syndrome in adults. Ann Surg. 2004;240:595-607.

25. Iglesias M, Martinez E, Badia JR, Macchiarini P. Extrapulmonary ventilation for unresponsive severe acute respiratory distress syndrome after pulmonary resection. Ann Thorac Surg. 2008;85:237-44.

26. Fischer S, Bohn D, Rycus P, Pierre AF, de Perrot M, Waddell TK, et al. Extracorporeal membrane oxygenation for primary graft dysfunction after lung transplantation: analysis of the Extracorporeal Life Support Organization (ELSO) registry. Heart Lung Transplant. 2007;26:472-7.

27. Vlasselaers D, Verleden GM, Meyns B, Van Raemdonck D, Demedts M, Lerut A, et al. Femoral venoarterial extracorporeal membrane oxygenation for severe reimplantation response after lung transplantation. Chest. 2000;118:559-61.

28. Meyers BF, Sundt TM 3rd, Henry S, Trulock EP, Guthrie T, Cooper JD, et al. Selective use of extracorporeal membrane oxygenation is warranted after lung transplantation. J Thorac Cardiovasc Surg. 2000;120:20-6.

29. Zenati M, Pham SM, Keenan RJ, Griffith BP. Extracorporeal membrane oxygenation for lung transplant recipients with primary severe donor lung dysfunction. Transpl Int. 1996;9:227-30.

30. Dahlberg PS, Prekker ME, Herrington CS, Hertz MI, Park SJ. Medium-term results of extracorporeal membrane oxygenation for severe acute lung injury after lung transplantation. J Heart Lung Transplant. 2004;23:979-84.

31. Van De Wauwer C, Neyrinck AP, Geudens N, Rega FR, Verleden GM, Verbeken E, et al. Retrograde flush following topical cooling is superior to preserve the non-heart-beating donor lung. Eur J Cardiothorac Surg. 2007; 31:1125-32.

32. Steen S, Ingemansson R, Eriksson L, Pierre L, Algotsson L, Wierup P, et al. First human transplantation of a nonacceptable donor lung after reconditioning ex vivo. Ann Thorac Surg. 2007;83:2191-4. 